\title{
Underdevelopment of the Human Hippocampus in Callosal Agenesis: An In Vivo Fetal MRI Study
}

\author{
(D). Knezović, (D) G. Kasprian, (D)A. Štajduhar, DE. Schwartz, DM. Weber, DG.M. Gruber, DP.C. Brugger, (DD. Prayer, and \\ (iD) Vukšić

\begin{abstract}
BACKGROUND AND PURPOSE: In subjects with agenesis of the corpus callosum, a variety of structural brain alterations is already present during prenatal life. Quantification of these alterations in fetuses with associated brain or body malformations (corpus callosum agenesis and other related anomalies) and so-called isolated cases may help to optimize the challenging prognostic prenatal assessment of fetuses with corpus callosum agenesis. This fetal MR imaging study aimed to identify differences in the size of the prenatal hippocampus between subjects with isolated corpus callosum agenesis, corpus callosum agenesis and other related anomalies, and healthy controls.
\end{abstract}

MATERIALS AND METHODS: Eighty-five in utero fetal brain MR imaging scans, (20-35 gestational weeks) were postprocessed using a high-resolution algorithm. On the basis of multiplanar T2-TSE sequences, 3D isovoxel datasets were generated, and both hippocampi and the intracranial volume were segmented.

RESULTS: Hippocampal volumes increased linearly with gestational weeks in all 3 groups. One-way ANOVA demonstrated differences in hippocampal volumes between control and pathologic groups (isolated corpus callosum agenesis: left, $P=.02$; right, $P=.04$; corpus callosum agenesis and other related anomalies: $P<.001)$. Differences among the pathologic groups were also present for both sides. Intracranial volume and right and left hippocampal volume ratios were different between corpus callosum agenesis cases and controls $(P<$ .001). When we corrected for intracranial volume, no differences were found between corpus callosum agenesis and other associated anomalies and isolated corpus callosum agenesis (left, $P=.77$; right, $P=.84$ ). Hippocampal size differences were more pronounced at a later gestational age.

CONCLUSIONS: Callosal agenesis apparently interferes with the normal process of hippocampal formation and growth, resulting in underdevelopment, which could account for certain learning and memory deficits in individuals with agenesis of the corpus callosum in later life.

ABBREVIATIONS: aACC = corpus callosum agenesis and other associated anomalies; ACC = agenesis of the corpus callosum; GW = gestational weeks; HF = hippocampal formation; iACC = isolated agenesis of the corpus callosum; ICV = intracranial volume

$\mathbf{A}^{\mathrm{s}}$ s the largest of the human forebrain commissures, containing $>190$ million axons, the corpus callosum begins to develop

Received September 20, 2018; accepted after revision January 14, 2019.

From the Croatian Institute for Brain Research (V.K., A.S.., M.V.), School of Medicine, University of Zagreb, Zagreb, Croatia; and Department of Biomedical Imaging and Image-Guided Therapy (G.K., E.S., M.W., D.P.) and Division of Anatomy (G.M.G., P.C.B.), Centre for Anatomy and Cell Biology, Medical University of Vienna, Vienna, Austria.

This study was supported by the Croatian Science Foundation under the project No. 7379 (M.V.) and by the European Union through the European Regional Development Fund, Operational Programme Competitiveness and Cohesion, grant agreement No. KK.01.1.1.01.0007, CoRE-Neuro.

Paper previously presented in part at: International Society of Ultrasound in Obstetrics \& Gynecology World Congress, September 16-19, 2017; Vienna, Austria; and the Federation of Neuroscience Societies Regional Meeting, September 20-23, 2017; Pécs, Hungary.

Please address correspondence to Gregor Kasprian, MD, Department of Biomedical Imaging and Image-Guided Therapy, Medical University of Vienna, Währinger Gürtel 18-20, 1090, Vienna, Austria; e-mail: gregor.kasprian@meduniwien.ac.at between 13 and 14 gestational weeks (GW) in the region of the ventral lamina reuniens and becomes fully mature at around 10 years of age. ${ }^{1,2}$ Many complex biologic processes are involved in its formation, such as birth and migration of commissural neurons, growth and elongation of their axons, crossing of the midline structures, synaptogenesis, and retraction of exuberant axons. Consequently, numerous human genetic disorders result in either complete or partial agenesis of the corpus callosum (ACC), which currently is the most common brain malformation and occurs in 1:4000 individuals. ${ }^{3}$ ACC is a very heterogeneous group of congenital malformations that can be found as isolated agenesis

\footnotetext{
- Indicates open access to non-subscribers at www.ajnr.org

$\equiv$ Indicates article with supplemental on-line tables.

Indicates article with supplemental on-line photo.

http://dx.doi.org/10.3174/ajnr.A5986
} 


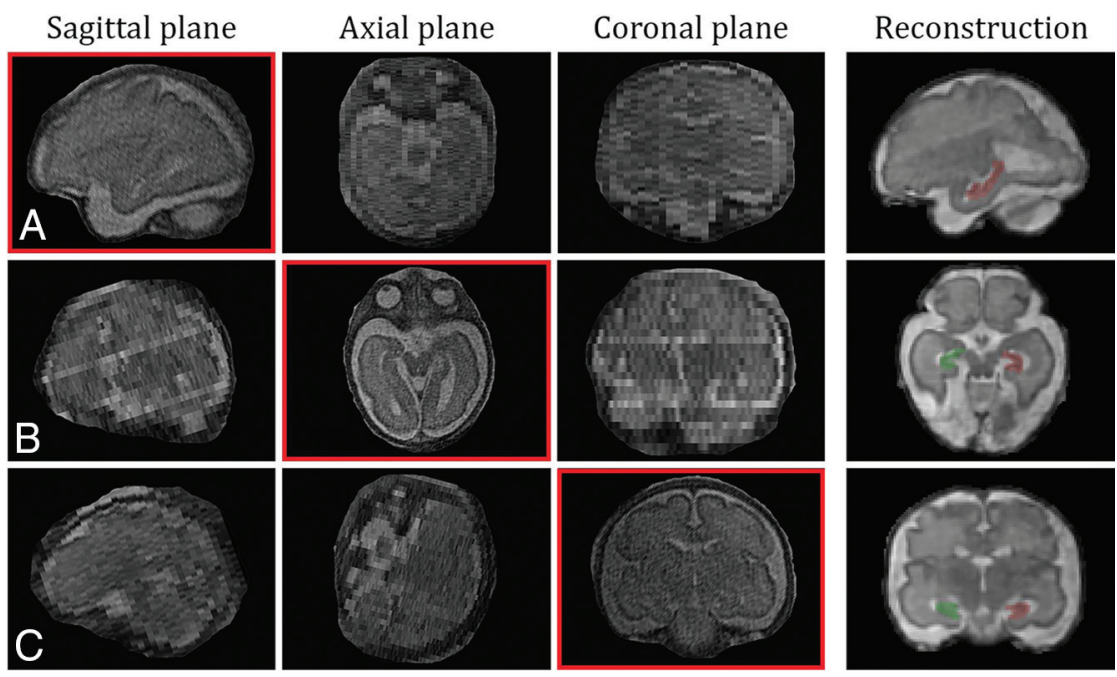

FIG 1. In vivo T2-weighted images of a control fetal brain, at $30 \mathrm{GW}$. An example of 3D-reconstructed MR imaging and segmentation borders for the left (red) and right (green) hippocampus in sagittal $(A)$, axial $(B)$, and coronal $(C)$ views.

of the corpus callosum (iACC) or can be associated with other brain and body malformations (aACC). When associated with other comorbid features, ACC is part of a wide range of genetic and chromosomal anomalies, toxic syndromes, or metabolic diseases and, therefore, has a severe clinical presentation. ${ }^{4}$ On the contrary, individuals with iACC have a more favorable prognosis, with a normal range of intellectual functioning. They display a typical pattern of neuropsychological and psychosocial deficits, which include impaired verbal learning and memory. ${ }^{4,5}$ Several studies have indicated that the absence of callosal fibers during development might influence the maturational processes of other brain regions; this influence can lead, for example, to a reduction in cortical thickness in some brain regions. ${ }^{6,7}$

Because the appearance and growth of callosal fibers coincide with the development of the human hippocampus, we hypothesized that ACC could, consequently, affect the proper formation of this structure, which is crucial for learning and memory functions. ${ }^{8-10}$ Therefore, in this retrospective MR imaging study, we aimed to determine the relationship between ACC and the development of the human hippocampal formation.

\section{MATERIALS AND METHODS \\ Fetuses and MR Imaging}

We retrospectively selected 85 fetal MR imaging datasets obtained from singleton pregnant women who underwent 1.5T fetal MR imaging examinations between January 2010 and March 2017, after a clinical indication for referral to the Department of Radiology, Medical University of Vienna. These women gave written, informed consent for a prenatal MR imaging study before the examination. The local ethics committee approved the study protocol (registration No. EK Nr. 2174/2016), and the research was conducted according to the principles expressed in the Declaration of Helsinki. All image data were pseudonymized before further analysis.

All MR imaging scans were re-reviewed by a pediatric neuroradiologist (G.K.) with extensive experience in fetal MR imaging. Inclusion criteria for the entire cohort were the following: available multiplanar T2-TSE sequences, acquired on a $1.5 \mathrm{~T} \mathrm{MR}$ imaging scanner (cardiac or body coil; Philips, Best, the Netherlands) in the left decubitus or supine position without sedation (orthogonal axial, coronal, and sagittal views; Fig 1) ( $\mathrm{TE}=140 \mathrm{~ms}$, FOV $=200-250 \mathrm{~mm}$, slice thickness $=$ 3-4.4 mm, 0.7-mm in-plane resolution), and gestational age between 20 and $35 \mathrm{GW}$.

The inclusion criteria for the healthy reference cases were the following: normal central nervous system findings at screening sonography and MR imaging examinations, no known genetic or chromosomal diseases, and normal fetal growth (On-line Table 1). The inclusion criteria for the iACC group were the following: complete or partial absence of the corpus callosum, no known genetic abnormality (as detected by a chromosomal microarray), and no additional body or brain malformation (as seen by screening sonography and/or fetal MR imaging) (On-line Table 2). The inclusion criteria for aACC were the following: complete or partial absence of the corpus callosum and additional body and/or brain malformation as detected by prenatal sonography and/or MR imaging (Online Table 3). Cases with motion-degraded T2WI were excluded from further analysis (On-line Figure). Fetal age was calculated from the first day of the woman's last menstrual cycle (gestational weeks) and determined with reference to a previous sonographic examination.

Overall, 85 fetuses were retrospectively selected. The control group consisted of 39 fetuses with normal brain development, with gestational ages ranging between 20 and $35 \mathrm{GW}$ (mean age, $28 \pm 3.8$ GW). Two groups with ACC comprised 31 cases with iACC, with a gestational age ranging between 22 and $34 \mathrm{GW}$ (mean age, $28 \pm 3.5$ GW) and 15 cases with aACC, with a gestational age ranging between 21 and $32 \mathrm{GW}$ (mean age, $26 \pm 3.7 \mathrm{GW}$ ).

\section{MR Imaging Postprocessing}

Fiducials placed manually at the distal ends of the lateral ventricles served as the initialization for an atlas-based brain-masking procedure on each anisotropic scan. The side of the scan was determined on the basis of the location of the stomach.

Three anisotropic scans in approximately orthogonal views were merged using a slice-wise motion-correction procedure and were used to reconstruct a high-resolution isotropic representation of the fetal brain (Fig 1). ${ }^{11}$ Automatic brain extraction was performed by nonlinear registration of a publicly available spatiotemporal atlas of fetal brain development ${ }^{12}$ to the reconstructed isotropic volume.

\section{Volume Measurement}

One reader (V.K.) manually performed the segmentation of the hippocampal formation (HF) using ITK-SNAP, Version 3.6, software (www.itksnap.org). ${ }^{13}$ For this study, we defined the HF as a structure that includes the dentate gyrus, the cornu ammonis, the 
subiculum, the fimbria, and the alveus (Fig 2). The anatomic borders used for segmentation of the fetal HF were based on prior studies $^{14,15}$ and were traced from the anterior head to the posterior tail. The left HF was always segmented before the right. The segmentation protocol would start in the sagittal plane, followed by the axial, and then was confirmed in the coronal plane (Fig 1). Note that although the HF in this study comprised the dentate gyrus, the cornu ammonis, the fimbria, the alveus, and the subiculum, these structures were indistinguishable (or partly distinguishable) on fetal MR imaging and, thus, were roughly sampled as a whole complex. ${ }^{14} \mathrm{~A}$ few brains had recording artifacts on some sections where borders of the HF were difficult to recognize. In these cases, it was necessary to navigate and compare several sections, forward and backward, to identify the shape and position of the structures where the borders were clear.

We obtained intracranial volume (ICV) from labeling the tissue types in the fetal brain using an atlas-based approach, using successive rigid and nonrigid registrations to a publicly available spatiotemporal atlas of fetal brain development. ${ }^{12}$ Available tissue segmentations in the atlas space were projected onto the individual case and served as frame for a graph-based segmentation procedure. ${ }^{16}$ ICV was then computed as the sum of the volumes of the gray matter, white matter, thalamus, germinal matrix, brain stem, cerebellum, ventricles, and CSF.

\section{Statistical Analysis}

Statistical analysis was preformed using SPSS Statistics for Windows, Version 24.0 (IBM, Armonk, New York). Absolute volumes
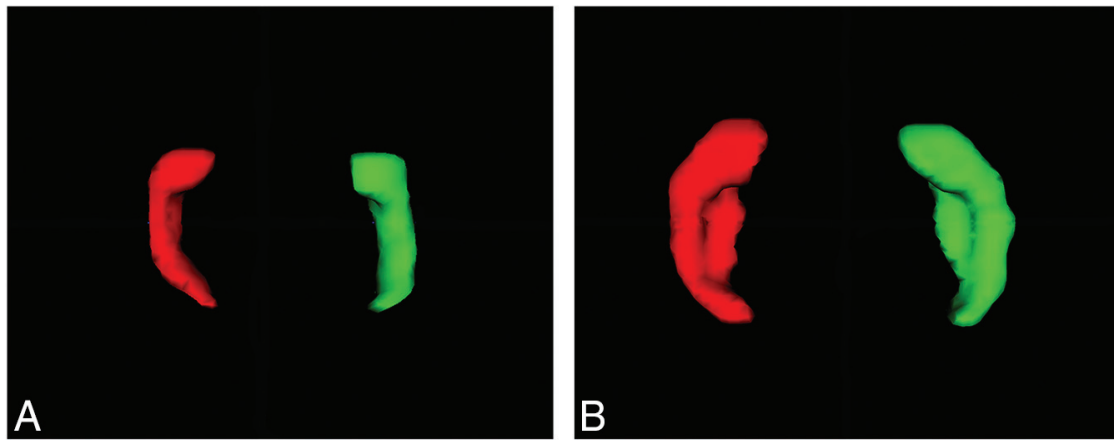

FIG 2. Axial view of a 3D surface model of the left (red) and right (green) hippocampus at $23 \mathrm{GW}$ $(A)$ and $30 \mathrm{GW}(B)$.
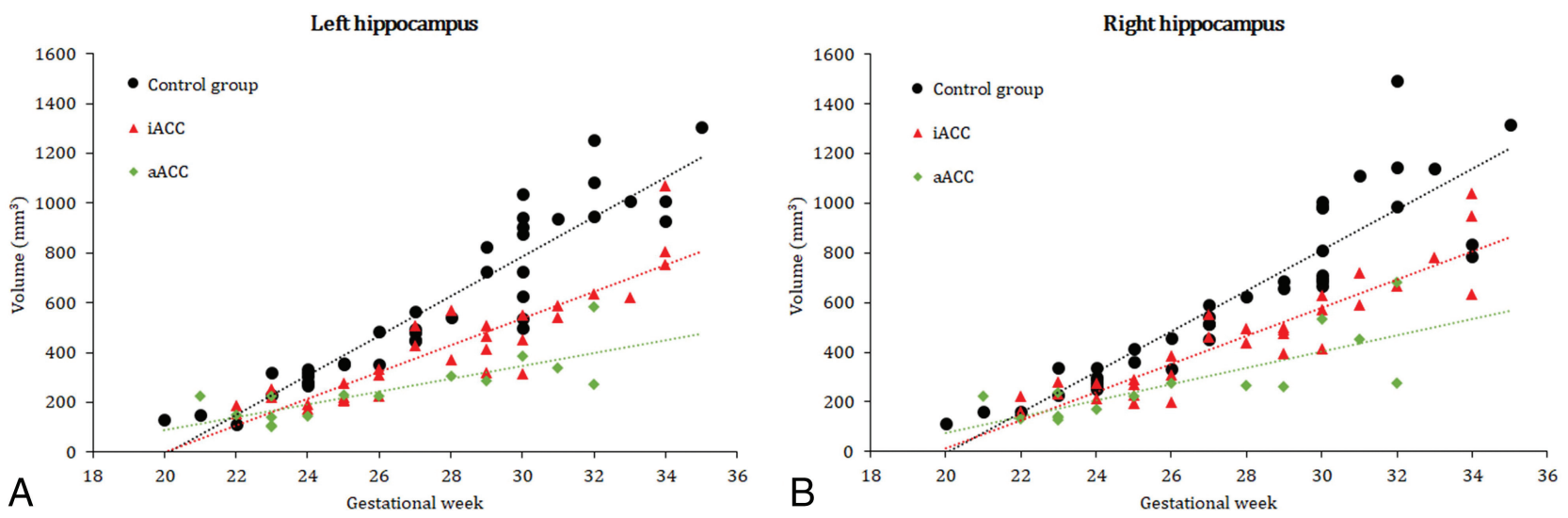

FIG 3. Scatterplots present absolute hippocampal volumes of controls, iACC, and aACC for the left $(A)$ and right $(B)$ hippocampus. (hippocampal volumes and ICV) are presented in cubic millimeters. Relative hippocampal volumes are ratios of the absolute hippocampal volume and ICV. Metric data are presented as mean \pm $\mathrm{SD}$ and counts, and percentages were used for nominal data. To determine differences between the ACC and iACC groups, as well as among age groups, we used a 2-way ANOVA. Paired $t$ tests were assessed to analyze the differences between the left and right hippocampal volumes. An intraclass correlation coefficient from repeated measurements of 18 randomly selected fetal brains, obtained 8 months later, was calculated as a measure of rater segmentation consistency. The level of significance was set at $\alpha=.05$.

\section{RESULTS}

\section{Segmentation Reliability}

An intraclass correlation coefficient was calculated from 18 repeated measurements $(21.2 \%)$. The intraclass correlation coefficient for the left hippocampus was 0.953 , and for the right, 0.906 .

As shown in Fig 3, absolute volumes of the left and right hippocampus demonstrated an almost linear increase in the control group, the iACC group, and the aACC group. No significant differences between the left and right hippocampal volumes were present in the control group and the aACC group (Table). However, the iACC group showed a significant difference between the left and the right hippocampal volumes, with the right hippocampus having higher values (Table). One-way ANOVA analysis revealed significant differences between the absolute hippocampal volumes of the control and the pathologic groups. When we compared the means of the left and right hippocampal volumes between the control group and the iACC group, the $P$ values were .02 and .04, and for the aACC group, the $P$ value was $<.001$. Differences between the pathologic groups were also present for both sides (left, $P=.005$; right, $P=.01$ ). When comparing absolute ICV, there was no difference between the control group and the pathologic groups (iACC, $P=.08$; aACC $P=.19)$. However, when we included the ratios of absolute left and right hippocam-

\section{Volume Analysis}


pal volumes and their ICVs in the analysis, we found a great difference between the control group and the pathologic groups $(P<$ $.001)$, while a comparison of the ratios of iACC and aACC did not show any differences (left, $P=.77$; right, $P=.84$ ).

To gain an even better insight into the extent of differences among our groups, we divided our data into 3 different time intervals: 20-25 GW, 26-30 GW, and 31-35 GW. Change of volume was significant, indicating that the difference among the 3 groups is not the same for different age groups. As can be seen

Mean volumes of hippocampi and $P$ values of left-right difference

\begin{tabular}{lccccc}
\hline Groups & $\begin{array}{c}\text { Left } \\
\text { Volume } \\
\left(\mathbf{m m}^{3}\right)\end{array}$ & SD & $\begin{array}{c}\text { Right } \\
\text { Volume } \\
\left(\mathbf{m m}^{3}\right)\end{array}$ & SD & $\begin{array}{c}\boldsymbol{P} \\
\text { Value }\end{array}$ \\
\hline & 601.21 & 328.40 & 621.51 & 347.10 & .180 \\
iACC & 416.23 & 216.20 & 454.58 & 223.80 & .003 \\
aACC & 248.07 & 125.20 & 276.27 & 160.90 & .070 \\
\hline
\end{tabular}
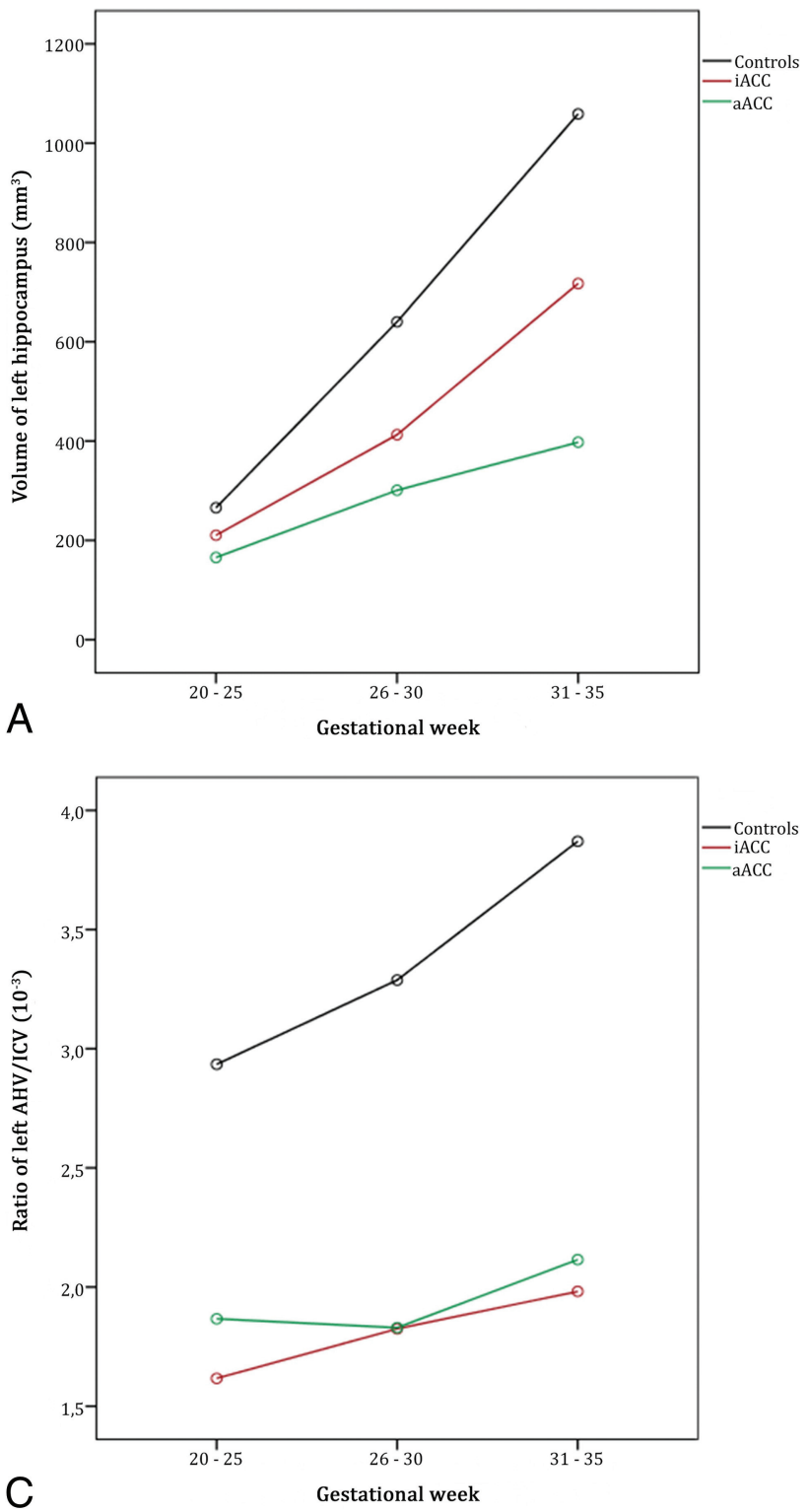

from Fig 4, the differences among groups increased with advancing age (Fig 4).

\section{DISCUSSION}

This quantitative prenatal neuroimaging study aimed to assess hippocampal development in human fetuses with complete and/or partial callosal agenesis. Compared with age-matched controls, there were reduced hippocampal volumes in both the iACC and aACC groups during the early second and third trimesters of pregnancy, suggesting the distinct impact of callosal formation on early hippocampal development.

\section{Correlation of the Development of the Corpus Callosum and the Hippocampal Formation}

The corpus callosum begins to develop between 13 and $14 \mathrm{GW}$ in the region of the ventral lamina reuniens and becomes fully mature at around 10 years of age. ${ }^{1,2}$ The first callosal fibers originate
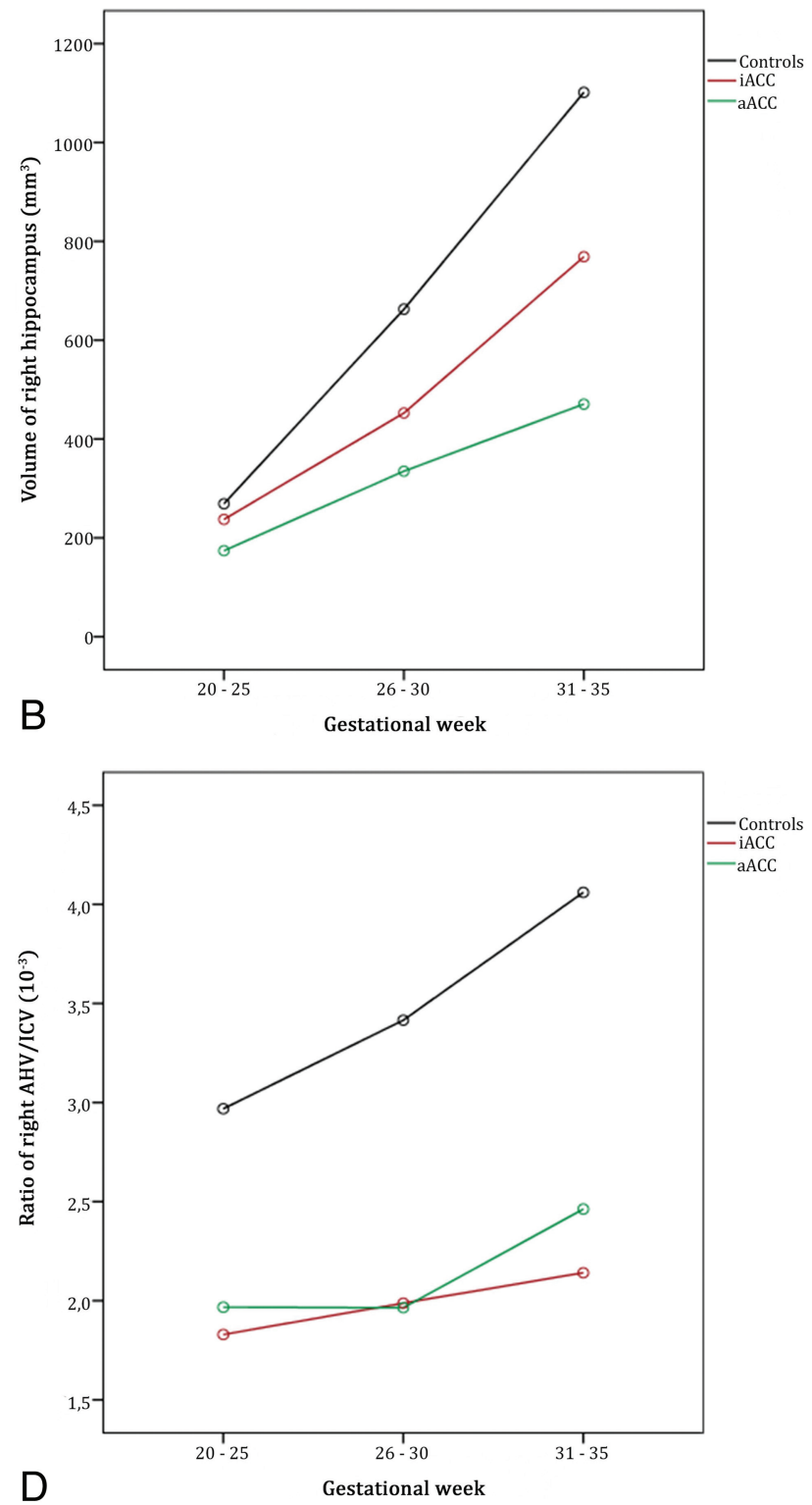

FIG 4. Moderation effects of age groups on volume group differences were found for the left $(A)$ and right (B) hippocampal volumes but not for the ratios of absolute hippocampal volume and ICV (C and D). 
from neurons located in the cingulate cortex, then cross the midline through the transient zone, known as the massa commissuralis, and grow toward the contralateral hemisphere, guided by many molecular factors and elaborate intercellular interactions. ${ }^{17-23}$ These initial growing pioneer axons serve as "guideposts" for later-arriving axons, which have to decide at several decision points to travel in the proper direction. ${ }^{19}$ All parts of the adult corpus callosum (rostrum, splenium, truncus, and genu) are visible around $20 \mathrm{GW}$. Moreover, after $20 \mathrm{GW}$, the corpus callosum continues with active growth, as well as with intense reorganizational processes, until $31 \mathrm{GW}$, characterized by the retraction of an abundant portion of the callosal fibers. ${ }^{24}$

The HF emerges around $10 \mathrm{GW}$ in the dorsomedial region of the cerebral hemisphere in the dorsal part of the lamina reuniens. ${ }^{8,9}$ Between 10 and $14 \mathrm{GW}$, before the formation of the corpus callosum, the HF occupies most of the medial hemispheric wall. ${ }^{25}$ However, around $14 \mathrm{GW}$, coincident with the emergence of the formation of the future corpus callosum, the supracallosal portion of the HF starts to display regressive changes. ${ }^{10}$ In adult vertebrates that lack a corpus callosum, the HF occupies a large portion of the medial surface, and the human HF manifests the same features until the outgrowth of the first callosal fibers. Between 14 and $15 \mathrm{GW}$, the HF starts to rotate as a result of the growth of surrounding brain structures, particularly the expansion of the corpus callosum. As an archicortical structure, the HF grows more rapidly than the surrounding neocortical regions. ${ }^{26} \mathrm{Be}-$ tween 18 and $20 \mathrm{GW}$, the rotation of the HF is nearly complete, and by this time, the hippocampal morphology begins to resemble that in the adult. After this period, the HF grows more slowly than other neocortical regions.

Is reduced hippocampal volume directly caused by the ACC or is it a completely independent event? The absence of callosal fibers during development is frequently associated with various limbic system malformations ${ }^{27}$ and an abnormal vertical orientation of the HF, and an arrest of the normal process of its inversion has been reported. ${ }^{28,29}$ In addition to its abnormal orientation, the HF appears to be hypoplastic in human patients lacking a corpus callosum. ${ }^{29-32}$ According to animal studies, the axonal collaterals of developing hippocampal neurons serve as guideposts for callosal axons while crossing the midline structures on their way to the contralateral hemisphere. ${ }^{19,33}$ Hence, abnormal hippocampal development may indirectly influence the proper growth and elongation of callosal fibers.

The formation of the corpus callosum is a very complex process, and disruption of any of the multiple steps involved in its development, such as the generation and migration of callosal neurons, axon elongation, glial patterning at the midline, or synaptogenesis, could lead to partial or complete absence of this commissure. It may therefore be assumed that the different genes responsible for guiding all these processes overlap significantly with those that are important for hippocampal development. One of the genes known to be crucial for both hippocampal and corpus callosum development is doublecortin, a gene required for normal neural migration. In both knockout doublecortin mice and doublecortin-mutated human patients, severe abnormalities of both of these structures were found, indicating a potentially conserved role for doublecortin in hippocampal and callosal development. ${ }^{34}$
Our data from control cases are in accordance with those in previous studies on fetal hippocampal development that demonstrate a linear increase in total hippocampal volume between 20 and $31 \mathrm{GW} \cdot{ }^{14,15}$ It is known that the HF is the fastest growing brain structure until $20 \mathrm{GW}$, but after $30 \mathrm{GW}$, its development lags behind neocortical regions. ${ }^{10}$ Because we found an arrest of hippocampal growth in the second phase of this period in subjects with ACC, the question is whether this decrease of hippocampal volume found in subjects with ACC is a result of slowing of normal growth in this period, or is it possibly a consequence of accelerated regressive changes? Thus, it is particularly difficult to decide whether the poorly formed hippocampus results from hypoplasia or from atrophy. Hypoplasia is defined as underdevelopment of an organ or tissue. Extending postnatal observations, ${ }^{29-32}$ we were able to demonstrate that the fetal hippocampus in cases of callosal agenesis mostly does not reach an age-appropriate size, even during prenatal life. Thus, the term "underdevelopment" or "hypoplasia" was used to describe the reduction in volume of this archicortical brain structure. Decreased size and connectivity of the cingulum have also been reported in ACC. ${ }^{35}$ Thus, as previously assumed, ${ }^{30}$ size differences and positional changes of the hippocampus in ACC may be a consequence of changes in the paralimbic cortices.

To our knowledge, there are no dedicated histologic analyses of the HF in fetal ACC. To ultimately clarify this point, histologic studies on postmortem human brain tissue have to be performed in the future, which will be able to precisely demonstrate possible changes in cellular and extracellular components in the HF in cases of ACC.

Finally, a certain limitation of this study is lack of postnatal or postmortem confirmation of prenatal findings in most of the ACC cases and healthy controls.

\section{CONCLUSIONS}

Our study suggests a relationship between abnormal commissural development and development of the human $\mathrm{HF}$ at prenatal stages of human life. In fetuses with ACC, the HF follows an abnormal anatomic developmental trajectory compared with healthy subjects, which ultimately results in an underdeveloped and smaller brain structure. The clinical impact of hippocampal underdevelopment on postnatal cognitive function in learning and memory-processing domains must be assessed by future postnatal follow-up studies.

Disclosures: Vinka Knezović-RELATED: Support for Travel to Meetings for the Study or Other Purposes: Croatian Science Foundation*; UNRELATED: Employment: Croatian Science Foundation. * Andrija Štajduhar-UNRELATED: Employment: Croatian Science Foundation. ${ }^{\star}$ Gregor Kasprian-UNRELATED: Consultancy: Bellaria Diagnose; Payment for Lectures Including Service on Speakers Bureaus: Shire, Biogen, Comments: speaker honorarium. Mario Vukšić-RELATED: Grant: Croatian Science Foundation. * *Money paid to the institution.

\section{REFERENCES}

1. Rakic P, Yakovlev PI. Development of the corpus callosum and cavum septi in man. J Comp Neurol 1968;132:45-72 CrossRef Medline

2. Giedd JN, Blumenthal J, Jeffries NO, et al. Development of the human corpus callosum during childhood and adolescence: a longitudinal MRI study. Prog Neuropsychopharmacol Biol Psychiatry 1999; 23:571-88 CrossRef Medline

3. Paul LK, Brown WS, Adolphs R, et al. Agenesis of the corpus 
callosum: genetic, developmental and functional aspects of connectivity. Nat Rev Neurosci 2007;8:287-99 CrossRef Medline

4. Paul LK, Erickson RL, Hartman J, et al. Learning and memory in individuals with agenesis of the corpus callosum. Neuropsychologia 2016;86:183-92 CrossRef Medline

5. Erickson RL, Paul LK, Brown WS. Verbal learning and memory in agenesis of the corpus callosum. Neuropsychologia 2014;60:121-30 CrossRef Medline

6. Abreu-Villaça Y, Silva WC, Manhães AC, et al. The effect of corpus callosum agenesis on neocortical thickness and neuronal density of BALB/cCF mice. Brain Res Bull 2002;58:411-16 CrossRef Medline

7. Beaulé V, Tremblay S, Lafleur LP, et al. Cortical thickness in adults with agenesis of the corpus callosum. Neuropsychologia 2015;77: 359-65 CrossRef Medline

8. Arnold SE, Trojanowski JQ. Human fetal hippocampal development, II: the neuronal cytoskeleton. J Comp Neurol 1996;367:293307 CrossRef Medline

9. Arnold SE, Trojanowski JQ. Human fetal hippocampal development, I: cytoarchitecture, myeloarchitecture, and neuronal morphologic features. J Comp Neurol 1996;367:274-92 CrossRef Medline

10. Kier EL, Fulbright RK, Bronen RA. Limbic lobe embryology and anatomy: dissection and MR of the medial surface of the fetal cerebral hemisphere. AJNR Am J Neuroradiol 1995;16:1847-53 Medline

11. Rousseau F, Oubel E, Pontabry J, et al. BTK: an open-source toolkit for fetal brain MR image processing. Comput Methods Programs Biomed 2013;109:65-73 CrossRef Medline

12. Serag A, Aljabar P, Ball G, et al. Construction of a consistent highdefinition spatio-temporal atlas of the developing brain using adaptive kernel regression. Neuroimage 2012;59:2255-65 CrossRef Medline

13. Yushkevich PA, Piven J, Hazlett HC, et al. User-guided 3D active contour segmentation of anatomical structures: significantly improved efficiency and reliability. Neuroimage 2006;31:1116-28 CrossRef Medline

14. Ge X, Shi Y, Li J, et al. Development of the human fetal hippocampal formation during early second trimester. Neuroimage 2015;119: 33-43 CrossRef Medline

15. Jacob FD, Habas PA, Kim K, et al. Fetal hippocampal development: analysis by magnetic resonance imaging volumetry. Pediatr Res 2011;69(5 Pt 1):425-29 CrossRef Medline

16. Makropoulos A, Aljabar P, Wright R, et al. Regional growth and atlasing of the developing human brain. Neuroimage 2016;125: 456-78 CrossRef Medline

17. Rash BG, Richards LJ. A role for cingulate pioneering axons in the development of the corpus callosum. J Comp Neurol 2001;434:147-57 CrossRef Medline

18. Richards LJ. Axonal pathfinding mechanisms at the cortical midline and in the development of the corpus callosum. Braz J Med Biol Res 2002;35:1431-39 CrossRef Medline

19. Richards LJ, Plachez C, Ren T. Mechanisms regulating the development of the corpus callosum and its agenesis in mouse and human. Clin Genet 2004;66:276-89 CrossRef Medline
20. Unni DK, Piper M, Moldrich RX, et al. Multiple Slits regulate the development of midline glial populations and the corpus callosum. Dev Biol 2012;365:36-49 CrossRef Medline

21. Srivatsa S, Parthasarathy S, Britanova O, et al. Unc5C and DCC act downstream of Ctip2 and Satb2 and contribute to corpus callosum formation. Nat Commun 2014;5:3708 CrossRef Medline

22. Shu T, Richards LJ. Cortical axon guidance by the glial wedge during the development of the corpus callosum. J Neurosci 2001;21: 2749-58 CrossRef Medline

23. Fothergill T, Donahoo AL, Douglass A, et al. Netrin-DCC signaling regulates corpus callosum formation through attraction of pioneering axons and by modulating Slit2-mediated repulsion. Cereb Cortex 2014;24:1138-51 CrossRef Medline

24. Innocenti GM, Price DJ. Exuberance in the development of cortical networks. Nat Rev Neurosci 2005;6:955-65 CrossRef Medline

25. Humphrey T. The development of the human hippocampal formation correlated with some aspects of its phylogenetic history. Evolution of the Forebrain 1966:104-06 https://link.springer.com/chapter/10.1007\% 2F978_1_4899-6527_1_11

26. Kostović I, Seress L, Mrzljak L, et al. Early onset of synapse formation in the human hippocampus: a correlation with Nissl-Golgi architectonics in 15- and 16.5-week-old fetuses. Neuroscience 1989;30: 105-16 CrossRef Medline

27. Atlas SW, Zimmerman RA, Bilaniuk LT, et al. Corpus callosum and limbic system: neuroanatomic MR evaluation of developmental anomalies. Radiology 1986;160:355-62 CrossRef Medline

28. Magee KR, Olson RN. The effect of absence of the corpus callosum on the position of the hippocampus and on the formation of Probst's bundle. J Comp Neurol 1961;117:371-82 CrossRef Medline

29. Sato N, Hatakeyama S, Shimizu N, et al. MR evaluation of the hippocampus in patients with congenital malformations of the brain. AJNR Am J Neuroradiol 2001;22:389-93 Medline

30. Baker LL, Barkovich AJ. The large temporal horn: MR analysis in developmental brain anomalies versus hydrocephalus. AJNR Am J Neuroradiol 1992;13:115-22 Medline

31. Küker W, Mayrhofer H, Mader I, et al. Malformations of the midline commissures: MRI findings in different forms of callosal dysgenesis. Eur Radiol 2003;13:598-604 Medline

32. Donmez FY, Yildirim M, Erkek N, et al. Hippocampal abnormalities associated with various congenital malformations. Childs Nerv Syst 2009;25:933-39 CrossRef Medline

33. Bohlen MO, Bailoo JD, Jordan RL, et al. Hippocampal commissure defects in crosses of four inbred mouse strains with absent corpus callosum. Genes Brain Behav 2012;11:757-66 CrossRef Medline

34. Kappeler C, Dhenain M, Phan Dinh Tuy F, et al. Magnetic resonance imaging and histological studies of corpus callosal and hippocampal abnormalities linked to doublecortin deficiency. J Comp Neurol 2007;500:239-54 CrossRef Medline

35. Nakata Y, Barkovich AJ, Wahl M, et al. Diffusion abnormalities and reduced volume of the ventral cingulum bundle in agenesis of the corpus callosum: a 3T imaging study. AJNR Am J Neuroradiol 2009; 30:1142-48 CrossRef Medline 